OPEN ACCESS

Edited by:

Ömer Erdeve,

Ankara University, Turkey

Reviewed by:

Mehmet Yekta Oncel,

Izmir Kâtip Çelebi University, Turkey

Mustafa N. Sulemanii,

Aga Khan University Hospital,

Nairobi, Kenya

*Correspondence:

Fuat Emre Canpolat

femrecan@gmail.com

TORCID:

Fuat Emre Canpolat orcid.org/0000-0001-9307-3003

Gülsüm Kadıoglu Şimşek orcid.org/0000-0003-4831-8950

Mehmet Büyüktiryak orcid.org/0000-0001-8937-4671

Nazmiye Bengü Karaçağlar orcid.org/0000-0001-6733-4871

Sarkhan Elbayiyev orcid.org/0000-0002-2113-5591

H. Gözde Kanmaz Kutman orcid.org/0000-0002-3177-9411

Specialty section: This article was submitted to Neonatology a section of the journa

Frontiers in Pediatrics

Received: 13 February 2020 Accepted: 10 March 2020

Published: 31 March 2020

Citation:

Canpolat FE, Kadıoğlu Şimşek G

Webbe J, Büyüktiryaki M, Karaçağlar NB, Elbayiyev S and Kanmaz Kutman HG (2020) Late Administration of Surfactant May Increase the Risk of Patent Ductus Arteriosus. Front. Pediatr. 8:130 doi: 10.3389/fped.2020.00130

\title{
Late Administration of Surfactant May Increase the Risk of Patent Ductus Arteriosus
}

\section{Fuat Emre Canpolat ${ }^{1 * \dagger}$, Gülsüm Kadıoğlu Şimşek ${ }^{1 \dagger}$, James Webbe ${ }^{2}$, Mehmet Büyüktiryaki ${ }^{1 \dagger}$, Nazmiye Bengü Karaçağlar ${ }^{1 \dagger}$, Sarkhan Elbayiyev ${ }^{1 \dagger}$ and H. Gözde Kanmaz Kutman ${ }^{1 \dagger}$}

${ }^{1}$ NICU, Department of Neonatology, Ankara City Hospital, University of Health Sciences, Ankara, Turkey, ${ }^{2}$ Neonatal Medicine, Imperial College London, London, United Kingdom

Introduction: Early rescue surfactant is the most effective way of administering surfactant but many infants still receive surfactant later. Our aim was to explore the association between timing of surfactant administration and the development of patent ductus arteriosus and other neonatal morbidities.

Materials and method: This retrospective study analyzed 819 preterm infants under 30 weeks of gestational age and under 1,500 g.

Results: Five hundred and ninety three infants received surfactant during the study period, of these 365 received it within $2 \mathrm{~h}$ of life (early group) and 228 received it after two h (late group). Patent ductus arteriosus was detected in 175 (48\%) of the early group and $168(74 \%)$ of the late group, $p=0.001$. Multinominal logistic regression analysis demonstrated that receiving surfactant after $2 \mathrm{~h}$ of life has a OR $3.5(2.2-5.6495 \% \mathrm{Cl})$ and a $p$-value of 0.001 for developing patent ductus arteriosus.

Conclusion: In this study population we observed that late surfactant administration is associated with increased risk of patent ductus arteriosus.

Keywords: surfactant, early rescue, patent ductus arteriosus, respiratory distress syndrome, preterm infant

\section{INTRODUCTION}

Respiratory distress syndrome (RDS) is the most common respiratory disease among preterm infants. Surfactant replacement therapy is an effective treatment for respiratory distress syndrome (1). Surfactant therapy has been shown to reduce disease severity and air leaks leading to improved survival (1). Although management has evolved gradually over the years early rescue surfactant administration is superior to late treatment (2). Previous trials showed that surfactant given earlier in the course of disease works better than later in terms of reducing air leaks (2) and avoiding mechanical ventilation if the intubate-surfactant-extubate (INSURE) technique is used (3). European Consensus Guideline 2019 recommended that early rescue surfactant should be standard (1) and there are occasions when surfactant should be given in the delivery suite, such as when intubation is needed for stabilization.

In some previous reports, early administration of surfactant is associated with shorter duration of ventilation, longer duration of continuous positive airway pressure and longer hospital stay but had little or no impact on bronchopulmonary dysplasia and/or mortality (4). There are limited and controversial data about the effect of surfactant timing on patent ductus arteriosus $(5,6)$. 
One recent trial with a large number of patients concluded that neonates in the late surfactant group who received more than one dose of surfactant were at higher risk of bronchopulmonary dysplasia, retinopathy of prematurity and patent ductus arteriosus requiring ligation (7).

Therefore, our aim was to investigate the relationship between timing of surfactant and development of patent ductus arteriosus. A secondary aim was to compare other neonatal morbidities among these groups.

\section{METHOD}

We retrospectively analyzed 819 cases of infants hospitalized in our neonatal intensive care unit during the study period (the years 2013-2018): 593 of these babies received surfactant. The infants were born at $<30$ weeks of gestation and had birth weight $\leq 1,500 \mathrm{~g}$. We divided the patients into two groups based on timing of surfactant therapy: the early surfactant group (365 infants) receiving surfactant within $2 \mathrm{~h}$ of life and the late group (228 infants) receiving it after $2 \mathrm{~h}$.

In this retrospective cohort, preterm infants with major congenital anomalies, infants with futile or palliative care, and missing information about surfactant administration time were excluded from the study.

Although the $\mathrm{FiO}_{2}$ requirement $>30 \%$ in infants with respiratory distress syndrome findings is considered to be an important predictor of the severity of respiratory distress syndrome and non-invasive ventilation failure, considering the high surfactant treatment rates in Turkey, we used administering surfactant in infants who require $\geq 40 \% \mathrm{FiO}_{2}$ during the study period (2013-2018) as our Turkish Guideline recommended (8). All very low birth weight preterm infants received continuous positive airway pressure (CPAP) as initial respiratory support in the delivery room.

\section{Definitions of Outcomes}

Echocardiographic criteria for a diagnosis of patent ductus arteriosus (PDA) were duct size $>1.5 \mathrm{~mm}$, a left atrium-to aortic $\operatorname{root}(\mathrm{LA}: \mathrm{Ao})>1.5$, left-to-right shunting of blood, end-diastolic reversal of blood flow in the aorta or poor cardiac function in addition to signs of PDA. Two-dimensional color Doppler echocardiography was performed using a GE Vivid 7 Pro, 10S transducer (GE Healthcare, Salt Lake City, Utah). Patent ductus arteriosus was defined as the requirement for medical treatment with evidence of echocardiographic findings at least once at any time during the NICU (Neonatal Intensive Care Unit) admission.

Cranial ultrasound imaging results were based on the worst finding at any given time for this patient before discharge: intraventricular hemorrhage grade III/IV was defined as intraventricular hemorrhage with ventricular enlargement as Papile et al. reported (9). Early onset sepsis was defined as isolation of bacterial, fungal, or viral organism from blood or cerebrospinal fluid in a symptomatic infant within 3 day of life and if more than 3 days defined as late onset sepsis. Bronchopulmonary dysplasia was defined as receiving supplemental oxygen at 36 weeks postmenstrual age (10). Retinopathy of Prematurity was defined according to the
International Classification of Retinopathy of Prematurity (ICROP) (11). Clinical chorioamnionitis was defined as inflammation of the chorion and amnion evidenced by presence of either maternal fever $\geq 38.4^{\circ} \mathrm{C}$ within $24 \mathrm{~h}$ before birth (irrespective of epidural analgesia), uterine tenderness, maternal leukocytosis of $>15,000 / \mathrm{mm}^{3}$, or explicitly mentioned obstetric concern at delivery. Information about histologic confirmation was not available. Days of oxygen, continuous positive airway pressure, or mechanical ventilation were counted during the primary NICU stay before discharge. Treatment of respiratory distress syndrome in our center was according to our local guidelines. Our center generally attempts to minimize invasive respiratory support with initiation of continuous positive airway pressure for all infants at risk of respiratory distress syndrome as soon as possible after birth in the delivery room, with the exception of extremely low gestational ages such as those who are $<26$ weeks. Continuous positive airway pressure support is the first line of respiratory support with the option of nasal intermittent mandatory ventilation or nasal intermittent positive pressure ventilation in case of increasing episodes of apnea and increased oxygen requirements. Intubation and surfactant administration follows the early symptomatic approach supported by large trials, generally with a cut-off of around 0.4 $\mathrm{FiO}_{2}$ with concomitant radiological changes, increased work of breathing and evidence of respiratory acidosis with $\mathrm{pH}<7.25$ and $\mathrm{pCO}_{2}>60 \mathrm{mmHg}$, followed by conventional mechanical ventilation with high frequency modes used generally as rescue therapy. We generally use less invasive surfactant administration procedure to give surfactant to spontaneously breathing preterms (12).

\section{Statistical Analysis}

Baseline demographics and the neonatal outcomes were compared among two surfactant timing groups: infants with early and late surfactant, using Chi-square test for categorical variables and Student $t$-test for continuous variables. To further examine the effect of late surfactant use, multiple logistic regression models were applied to compare the primary and secondary outcomes between the surfactant timing groups. The odds ratio (95\% confidence interval) of outcomes were determined based on the final multiple logistic regression models derived by backward variable selection procedure with inclusion criterion of 0.05 . The factors for the full model included gender, cesarean section, antenatal steroid use as factors, gestational age, and birth weight as covariates. The data management and all statistical analyses were performed using SPSS for Windows version 22, IBM (USA). A two-sided significant level of 0.05 was used.

\section{RESULTS}

After exclusion, 819 preterm infants were analyzed in this retrospective study. Five hundred and ninety three infants received surfactant during the years 2013-2018, of these 365 received it within $2 \mathrm{~h}$ of life (early rescue group, first group) and 228 received it after two h (late group, second group). Mean gestational age was $27 \pm 1.7$ and $27.3 \pm 1.5(p=0.1)$ weeks 
and mean birth weight was $945 \pm 248$ vs. $974 \pm 232 \mathrm{~g}(p=$ $0.25)$, respectively. In the first group $186(51 \%)$ and $111(49 \%)$ in second group were boys. Antenatal steroid ratio was $68 \%$ in early and $73 \%$ in late group. Other obstetric risks were similar and shown in Table 1. Patent ductus arteriosus was detected in $175(48 \%)$ of the early group and $168(74 \%)$ of the late group, $p=0.001$. All other early neonatal outcomes were compared in Table 2. Multinominal logistic regression analysis was made

TABLE 1 | Basic clinical characteristics of study groups.

\begin{tabular}{lccc}
\hline & $\begin{array}{c}\text { Early surfactant } \\
\boldsymbol{n}=\mathbf{3 6 5}\end{array}$ & $\begin{array}{c}\text { Late surfactant } \\
\boldsymbol{n}=\mathbf{2 2 8}\end{array}$ & $\boldsymbol{p}$ \\
\hline Gestational age, weeks $\pm \mathrm{SD}$ & $27 \pm 1.7$ & $27.3 \pm 1.5$ & 0.1 \\
Birth weight, $\mathrm{g} \pm \mathrm{SD}$ & $945 \pm 248$ & $974 \pm 232$ & 0.25 \\
Male gender, $n$ (\%) & $186(51)$ & $111(49)$ & 0.64 \\
Antenatal steroids, $n(\%)$ & $248(68)$ & $166(73)$ & 0.3 \\
Chorioamnionitis, $n(\%)$ & $43(12)$ & $20(9)$ & 0.251 \\
Preeclampsia, $n(\%)$ & $69(19)$ & $38(17)$ & 0.77 \\
Gestational diabetes, $n(\%)$ & $14(4)$ & $7(3)$ & 1.0 \\
Cesarean section, $n(\%)$ & $292(80)$ & $175(77)$ & 0.43 \\
Multiple gestation, $n(\%)$ & $80(22)$ & $48(21)$ & 0.494 \\
Rupture of membranes, $n(\%)$ & $70(19)$ & $29(13)$ & 0.182 \\
\hline
\end{tabular}

TABLE 2 | Comparison of clinical outcomes of study population.

\begin{tabular}{|c|c|c|c|}
\hline & $\begin{array}{l}\text { Early surfactant } \\
\qquad n=365\end{array}$ & $\begin{array}{l}\text { Late surfactant } \\
\qquad n=228\end{array}$ & $p$ \\
\hline Apgar score & $5(2-8)$ & $5(1-8)$ & $0.827^{\star}$ \\
\hline Last day of life receiving oxygen & $42 \pm 24$ & $40 \pm 21$ & 0.597 \\
\hline \multicolumn{4}{|l|}{ Respiratory support at 28th day } \\
\hline Supplemental oxygen & $186(51)$ & $120(53)$ & 0.639 \\
\hline Non-invasive ventilation & $76(21)$ & $45(20)$ & \\
\hline nIMV & $55(15)$ & $38(16)$ & \\
\hline Mechanical ventilation & $54(15)$ & $32(14)$ & \\
\hline $\begin{array}{l}\text { Last day of life receiving respiratory } \\
\text { support, days } \pm S D\end{array}$ & $21 \pm 18$ & $19 \pm 15$ & 0.373 \\
\hline Duration of CPAP, days $\pm \mathrm{SD}$ & $5.7 \pm 6$ & $7.6 \pm 7$ & 0.011 \\
\hline Duration of nIMV, days \pm SD & $3.1 \pm 5$ & $3.8 \pm 5$ & 0.236 \\
\hline Duration of MV, days $\pm \mathrm{SD}$ & $6.2 \pm 10$ & $7.7 \pm 15$ & 0.251 \\
\hline Air leaks, $n(\%)$ & $10(2.7)$ & $8(3.5)$ & 0.282 \\
\hline PDA, $n(\%)$ & $175(48)$ & $168(74)$ & 0.001 \\
\hline Surfactant more than 2 doses & $95(26)$ & $68(30)$ & 0.313 \\
\hline Early neonatal sepsis, $n$ (\%) & $80(22)$ & $57(25)$ & 0.386 \\
\hline Late onset sepsis, $n(\%)$ & $131(36)$ & $75(33)$ & 0.456 \\
\hline BPD, moderate and severe, $n(\%)$ & $58(16)$ & $38(17)$ & 0.8 \\
\hline IVH Grade III and IV, n (\%) & $58(16)$ & $27(12)$ & 0.17 \\
\hline ROP, $n(\%)$ & $36(10)$ & $32(14)$ & 0.12 \\
\hline Day of discharge, days $\pm S D$ & $69 \pm 21$ & $70 \pm 22$ & 0.68 \\
\hline Mortality, $n(\%)$ & $36(10)$ & $29(11)$ & 0.182 \\
\hline
\end{tabular}

CPAP, continuous positive airway pressure; nIMV, nasal intermittent mandatory ventilation; MV, mechanical ventilation; PDA, patent ductus arteriosus; BPD, bronchopulmonary dysplasia; $I \mathrm{VH}$, intraventricular hemorrhage; $R O P$, retinopathy of prematurity; $S D$, standard deviation; *non-parametric test.

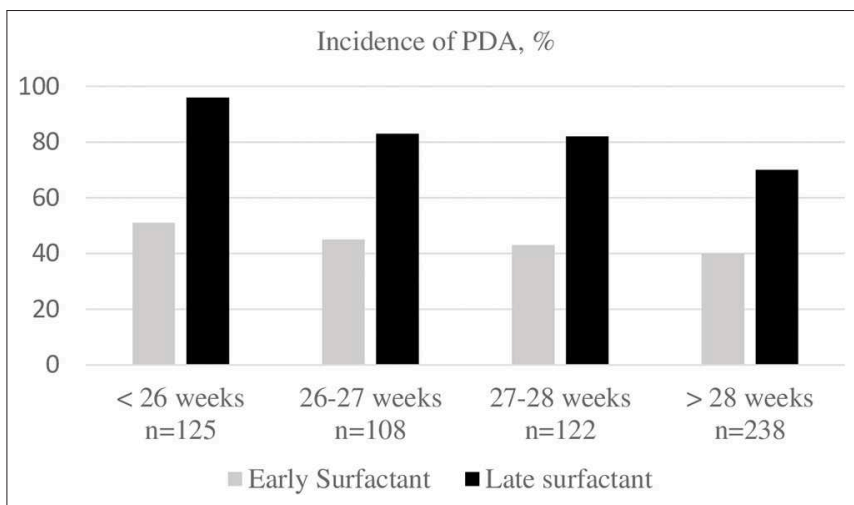

FIGURE 1 | Patent ductus arteriosus incidence among gestational ages compared by early vs. late surfactant timing. PDA, patent ductus arteriosus.

with antenatal steroids (even no difference between groups) and receiving surfactant (any time) as risk factors and gestational age and birth weight as covariates. This analysis found that receiving surfactant after $2 \mathrm{~h}$ of life has a OR $3.5(2.2-5.6495 \% \mathrm{CI})$ and a $p$-value of 0.001 for developing patent ductus arteriosus. We grouped and analyzed patients according to gestational age and this is demonstrated in Figure 1.

\section{DISCUSSION}

According to the results of this study, administering surfactant after the first $2 \mathrm{~h}$ of life is associated with higher frequency of patent ductus arteriosus. Although similar studies have been published previously $(6,7)$, this study is the first in the literature to draw attention to this subject. In addition, the duration of continuous positive airway pressure was slightly but statistically longer in the group with late surfactant administration compared to the group with early administration.

Surfactant therapy is now accepted as the standard treatment method for respiratory distress syndrome and reduces mortality $(1,8)$. Recommendations for surfactant therapy include preferring natural surfactant preparations, applying it as targeted early rescue therapy, and administering by non-invasive methods if the patient is breathing spontaneously $(1,8)$.

However, the principles of surfactant administration may vary from country to country or between different guidelines $(1,6,8$, $13,14)$. The available evidence suggests that if the patient needs surfactant administering it as early as possible is most beneficial $(2,15)$. There is also evidence on non-invasive ventilation in the first $72 \mathrm{~h}$ of life reduces the need for invasive ventilation and surfactant requirement (16), these all evidences are a part of need for surfactant. The advantages of early surfactant administration over late administration can be summarized as lower incidence of air leaks, less need for mechanical ventilation and a decreased risk of neonatal mortality and bronchopulmonary dysplasia $(1,2)$. In recent years, decisions regarding whether or not to administer surfactant therapy have been based primarily on an oxygen requirement threshold according to international guidelines (1). This threshold, which is $40 \%$ according to old 
guidelines, has also been applied in Turkey and in the present study (8). In more recent guidelines, this figure has been reduced to $30 \%$, which suggests that surfactant will now be given much earlier and can be interpreted as promoting early surfactant administration (1).

Although early surfactant administration is recommended based on the findings of numerous trials and other studies, it is not always possible in clinical practice. Some patients may have very good clinical condition, normal or near-normal x-rays, low oxygen requirement, and very little need of respiratory support in the first hours. For reasons that are not well-understood, at postnatal age of 6-12 h or later these infants show increased oxygen requirement that cannot be met by pressure support ventilation, and the need for surfactant can arise even though it was not needed before.

This may be attributed to several factors, including the conditions of postnatal care, effectiveness of continuous positive airway pressure, the interface, and depletion and inadequacy of the infant's endogenous surfactant. If continuous positive airway pressure is not effective enough, the infant loses alveolar patency in a matter of hours and has higher tendency toward hypoxia, resulting in lung parenchyma that requires surfactant. With the administration of surfactant in addition to the effects of hypoxia on the lungs, there is a sudden reduction in pulmonary pressure and the ductus arteriosus remains patent. Surfactant administered at a later time causes sudden hemodynamic changes in a lung that has gradually deteriorated and entered this vicious cycle within hours.

This study has certain limitations. One of these is its retrospective nature. Furthermore, the fact that it was conducted at a single center based on a single guideline can also be considered a limitation. Nevertheless, our patient sample is sufficient, and to the best of our knowledge, there is no other study in the literature examining the impact of late surfactant

\section{REFERENCES}

1. Sweet DG, Carnielli V, Greisen G, Hallman M, Ozek E, Te Pas A, et al. European Consensus Guidelines on the Management of Respiratory Distress Syndrome - 2019 upatent ductus arteriosuste. Neonatology. (2019) 115:43251. doi: 10.1159/000499361

2. Bahadue FL, Soll R. Early versus delayed selective surfactant treatment for neonatal respiratory distress syndrome. Cochrane Database Syst Rev. (2012) 11:CD001456. doi: 10.1002/14651858.CD001456.pub2

3. Verder H, Albertsen P, Ebbesen F, Greisen G, Robertson B, Bertelsen A, et al. Nasal continuous positive airway pressure and early surfactant therapy for respiratory distress syndrome in newborns of less than 30 weeks' gestation. Pediatrics. (1999) 103:E24. doi: 10.1542/peds.103.2.e24

4. Premnath D, Kent AL, Bajuk B, Abdel-Latif ME, NSW and the ACT Neonatal Intensive Care Audit Group. Does timing of initial surfactant treatment make a difference in rates of chronic lung disease or mortality in premature infants? An observational regional study. J Matern Fetal Neonatal Med. (2016) 29:91-8. doi: 10.3109/14767058.2014.987747

5. Dilmen U, Özdemir R, Tatar Aksoy H, Uras N, Demirel N, Kirimi E, et al. Early regular versus late selective poractant treatment in preterm infants born between 25 and 30 gestational weeks: a prospective randomized multicenter study. J Matern Fetal Neonatal Med. (2014) 27:4115. doi: 10.3109/14767058.2013.818120 administration on patent ductus arteriosus in a patient group of this size.

In conclusion, our findings support the well-established practice of early surfactant administration from a different angle. Early surfactant administration leads to a lower incidence of patent ductus arteriosus and reduced the need for respiratory support (continuous positive airway pressure duration) in neonates. We did not observe any differences between the groups in terms of bronchopulmonary dysplasia or other morbidities, but prospective studies based on new guidelines may provide stronger evidence as to whether such differences exist.

\section{DATA AVAILABILITY STATEMENT}

The datasets generated for this study are available on request to the corresponding author.

\section{ETHICS STATEMENT}

The studies involving human participants were reviewed and approved by Zekai Tahir Burak Hospital Ethical Committee. Written informed consent to participate in this study was provided by the participants' legal guardian/next of kin.

\section{AUTHOR CONTRIBUTIONS}

FC, GK, and MB collected data. NK and SE patient management, data management, and entering data. GK and FC crtitcal review. HK and FC made statistical analysis. JW made review.

\section{FUNDING}

This research did not receive any specific grant from funding agencies in the public, commercial, or not-for-profit sectors.
6. Kim SM, Park YJ, Chung SH, Choi YS, Kim CH, Bae CW. Early prophylactic versus late selective use of surfactant for respiratory distress syndrome in very preterm infants: a collaborative study of 53 multi-center trials in Korea. $J$ Korean Med Sci. (2014) 29:1126-31. doi: 10.3346/jkms.2014.29.8.1126

7. Stritzke A, Mohammad K, Shah PS, Ye XY, Bhandari V, Akierman A, et al. Use and timing of surfactant administration: impact on neonatal outcomes in extremely low gestational age infants born in Canadian Neonatal Intensive Care Units. J Matern Fetal Neonatal Med. (2018) 31:28629. doi: 10.1080/14767058.2017.1358266

8. Özkan H, Erdeve Ö, Kutman HGK. Turkish Neonatal Society guideline on the management of respiratory distress syndrome and surfactant treatment. Turk Pediatri Ars. (2018) 53:S45-54. doi: 10.5152/TurkPediatriArs.2018. 01806

9. Papile LA, Burstein J, Burstein R, Koffler H. Incidence and evolution of subependymal and intraventricular hemorrhage: a study of infants with birth weights less than 1,500 gm. J Pediatr. (1978) 92:52934. doi: 10.1016/S0022-3476(78)80282-0

10. Bancalari E, Jain D. Bronchopulmonary dysplasia: can we agree on a definition? Am J Perinatol. (2018) 35:537-40. doi: 10.1055/s-0038-1637761

11. International Committee for the Classification of Retinopathy of Prematurity. The International classification of retinopathy of prematurity revisited. Arch Ophthalmol. (2005) 123:991-9. doi: 10.1001/archopht. 123.7.991 
12. Kanmaz HG, Erdeve O, Canpolat FE, Mutlu B, Dilmen U. Surfactant administration via thin catheter during spontaneous breathing: randomized controlled trial. Pediatrics. (2013) 131:e502-9. doi: 10.1542/peds. 2012-0603

13. Shah PS, Seidlitz W, Chan P, Yeh S, Musrap N, Lee SK, et al. Internal audit of the Canadian Neonatal Network Data Collection System. Am J Perinatol. (2017) 34:1241-9. doi: 10.1055/s-0037-1603325

14. Banerjee S, Fernandez R, Fox GF, Goss KCW, Mactier H, Reynolds P, et al. Surfactant replacement therapy for respiratory distress syndrome in preterm infants: United Kingdom national consensus. Pediatr Res. (2019) 86:12-4. doi: 10.1038/s41390-019-0344-5

15. Krause MF, Hoehn T. Timing of surfactant administration determines its physiologic response in a rabbit model of airway lavage. Biol Neonate. (2000) 77:196-202. doi: 10.1159/000014216

16. Oncel MY, Arayici S, Uras N, Alyamac-Dizdar E, Sari FN, Karahan S, et al. Nasal continuous positive airway pressure versus nasal intermittent positive-pressure ventilation within the minimally invasive surfactant therapy approach in preterm infants: a randomised controlled trial. Arch Dis Child Fetal Neonatal Ed. (2016) 101:F323-8. doi: 10.1136/archdischild-2015308204

Conflict of Interest: The authors declare that the research was conducted in the absence of any commercial or financial relationships that could be construed as a potential conflict of interest.

Copyright (C) 2020 Canpolat, Kadıŏ̆lu Şimşek, Webbe, Büyüktiryaki, Karaçağlar, Elbayiyev and Kanmaz Kutman. This is an open-access article distributed under the terms of the Creative Commons Attribution License (CC BY). The use, distribution or reproduction in other forums is permitted, provided the original author(s) and the copyright owner(s) are credited and that the original publication in this journal is cited, in accordance with accepted academic practice. No use, distribution or reproduction is permitted which does not comply with these terms. 